\title{
Psychosocial and productivity impact of caring for a child with peanut allergy
}

\author{
Sarah Acaster ${ }^{1}$, Katy Gallop 1 , Jane de Vries ${ }^{2,3}$, Anne Marciniak ${ }^{3}$, Robert Ryan ${ }^{3}$, Andrea Vereda ${ }^{3}$ \\ and Rebecca Knibb ${ }^{4^{*}}$ (D)
}

\begin{abstract}
Background: Limited previous research has assessed the psychosocial burden and productivity impact of caring for a child with peanut allergy and factors associated with burden. The objective of this research was to explore caregiver burden in terms of psychosocial and productivity impact of caring for a child with peanut allergy, the influence of caregiver and child gender on caregiver burden, and factors predicting caregiver burden in peanut allergy.
\end{abstract}

Methods: A cross-sectional survey of caregivers of children with peanut allergy was conducted in the United Kingdom, and included sociodemographic and clinical questions, EQ-5D, Hospital Anxiety and Depression Scale, Food Allergy Quality of Life-Parental Burden, Food Allergy Independent Measure, and productivity questions.

Results: One hundred caregivers (55\% female) of children with peanut allergy (aged 4-15 years) completed the survey. Male and female caregivers reported mean levels of anxiety significantly higher than United Kingdom population norms. Caregivers of children with severe peanut allergy reported significant impacts on their careers and health-related quality of life. Neither caregiver nor child gender impacted burden, indicating that male and female caregivers are equally anxious and suffer the same level of negative career, productivity, and health-related quality-of-life impact due to their child's peanut allergy. Caregivers' perceived risk of outcomes related to their child's peanut allergy (e.g., death or severe reaction) as measured by the Food Allergy Independent Measure independently predicted burden.

Conclusions: Caregivers of children with peanut allergy in the United Kingdom experience health-related quality-oflife, psychosocial, and productivity burden; this study demonstrates the high levels of anxiety reported by both male and female caregivers.

Keywords: Peanut allergy, Caregiver, Parental burden, Health-related quality of life, Productivity, Psychosocial burden

\section{Background}

Peanut allergy affects between $0.6 \%$ and $1 \%$ of the adult population and between $1 \%$ and $3 \%$ of children in the developed world [1, 2], and studies suggest the prevalence is increasing in the United Kingdom (UK) [3]. There is currently no approved treatment for peanut allergy outside of the United States; therefore, management

*Correspondence: r.knibb@aston.ac.uk

${ }^{4}$ Department of Psychology, School of Life and Health Sciences, Aston University, Aston Triangle, Birmingham B4 7ET, UK

Full list of author information is available at the end of the article requires strict avoidance of peanuts and emergency treatment in the case of accidental ingestion.

Previous research has identified several areas of caregivers' health-related quality of life (HRQL) that are affected by having a child with food allergy. Parents of children with food allergies report significantly greater emotional impact, impact on parental time, and limitations in usual family activities than do population norms in the United States [4]. Similarly, parents of children with food allergies report significantly greater emotional impact [5] and effect on social relationships [6] than do parents of children with no allergic diseases. 
An older study that used a convenience sample in comparison with rheumatological disease, a condition that is very dissimilar to allergy, found impairment of family relations reported by parents of children with peanut allergy [7]. In addition, parent-reported food allergy is associated with caregiver stress, although parents of children who have undergone an oral food challenge report significantly less stress [8]. Even with suspected food allergy prior to clinical diagnosis, the level of anxiety in parents was significantly higher than in those who had just been diagnosed with a chronic illness [9].

Many factors have been associated with increased caregiver burden for those with food allergies. Food allergy characteristics, including type and number of food allergens, type and severity of symptoms, previous anaphylactic reactions, adrenaline autoinjector use, and oral food challenge history have been found to influence parental burden [8, 10-14]. In addition, factors such as lower caregiver income and education, child's age and age at most severe reaction, parental self-efficacy for food allergy management, and negativity experienced in social relationships have also been shown to influence caregiver burden $[11,12,14,15]$.

Limited research has explored whether caregiver gender influences the amount of burden experienced by caregivers of children with food allergies; some evidence suggests gender does make a difference. One study found that mothers reported significantly lower HRQL than fathers but greater empowerment, regardless of allergen severity, type of food allergy, or comorbidities [16]. Another study found that mothers reported significantly more negative impact than fathers regarding meal preparation, family social activities, stress, and free time, and significantly greater involvement in allergy-related care. However, fathers who reported more frequent medical appointment attendance perceived meal preparation as being significantly more impacted by food allergies than fathers who were less involved, suggesting that differences in impact may be related to the level of involvement in day-to-day activities rather than gender [17]. In peanut allergy specifically, a study of families including a child with peanut allergy found that mothers reported worse HRQL and more stress and anxiety than did fathers [18].

As outlined above, much previous research on caregiver impact has been conducted in food allergy in general, with limited studies focused on peanut allergy specifically. One study in peanut allergy found that a subset of parents of a child with peanut allergy experienced high levels of parenting stress [19]. Parents of a child with peanut allergy have also expressed difficulties with their child's transition to independence and their own subsequent loss of control [20], suggesting that the child's age may influence HRQL burden for caregivers. As discussed previously, one study found that caregiver gender may also influence caregiver burden in peanut allergy [18]. No research has previously explored the impact of peanut allergy specifically on caregiver work or productivity, although one survey of caregivers of children with any food allergy found that a small proportion (9\%) reported a work-related impact of their child's food allergy, such as career restrictions, job change, or job loss [21].

Thus, given the limited research on caregiver burden in peanut allergy specifically, the objectives of this study were to (1) describe the psychosocial and productivity impact of caring for a child with peanut allergy, (2) explore the effect of caregiver and child gender on caregiver HRQL, and (3) examine which factors predict caregiver HRQL in peanut allergy. To explore these objectives, we report on results from a survey of caregivers of children with peanut allergy aged 4 to 15 years in the UK.

\section{Methods \\ Study design}

This study used a cross-sectional online survey to explore burden in caregivers of children aged 4 to 15 years with peanut allergy in the UK. The study was reviewed and approved by the Freiburg Ethics Commission International (FECI) prior to participant recruitment (FECI code: 017/1938; date: 20 November 2017).

\section{Participants}

Participants were recruited through a specialist survey recruitment panel. Participants were eligible for the study if they were a parent or primary caregiver of a child (aged 4-15 years) with a medically diagnosed peanut allergy, who had experienced at least one reaction to peanuts in their day-to-day life (not a food challenge). In order to ensure diversity in the severity of peanut allergy in the sample, a quota was set for a minimum of $80 \%$ of participants who perceived the severity of their child's peanut allergy as moderate or severe, with a minimum of $25 \%$ in the moderate/severe population having needed to use an adrenaline autoinjector, and a minimum of $10 \%$ having experienced a life-threatening event.

\section{Procedure and measures}

Eligible participants were provided with information about the study purpose and procedures. Participants were asked to read the information provided, and if interested in participating, were asked to give their consent online prior to completing the online survey. 
Participants received nominal reimbursement for participating in the study.

The survey consisted of sociodemographic questions about the caregiver and their child and clinical questions about the child's peanut allergy. The clinical questions included the caregivers' perception of the severity of their child's peanut allergy (mild, moderate, or severe), caregivers' confidence in managing their child's reactions to peanut allergy ("not at all confident" to "very confident"), the number of reactions to peanut their child experienced in the last 12 months and in the child's lifetime, the type of treatment received in the last 12 months and in their lifetime, and whether their child experienced a life-threatening reaction to peanut in the last 12 months and in their lifetime. Participants were also asked about the impact on their productivity due to their child's peanut allergy, including the number of days they were absent from work in the last 12 months, the number of days their productivity was impacted in the past 12 months, and whether their career was impacted. The survey also included validated measures of caregiver HRQL (EQ-5D-5L, Food Allergy Quality of Life-Parental Burden [FAQL-PB]) and caregiver anxiety and depression (Hospital Anxiety and Depression Scale [HADS]) and a measure of caregiver food allergy-related expectation of outcome (Food Allergy Independent Measure-Parent Form [FAIM-PF]).

The EQ-5D-5L [22] is a generic, preference-based health status measure. Participants report their current health on five dimensions (mobility, self-care, pain and discomfort, usual activities, and anxiety and depression) with five response options for each dimension, from "no problems" to "extreme problems." Responses are converted into a single index value that can be used in cost-effectiveness analyses, where a score of 1 represents "full health" and a score of 0 represents "dead." The instrument was scored using the van Hout et al. [23] mapping algorithm, which maps to the UK value set [24]. Participants also rate their current health on a 0 to 100 visual analogue scale (VAS).

The FAQL-PB [25] was developed to assess burden for parents with food-allergic children. The FAQL-PB scale is a self-administered 17-item questionnaire. Each item is presented on a 7-point Likert scale ranging from 1 (not troubled) to 7 (extremely troubled). Items are summed to provide a total continuous score; higher scores indicate greater parental burden. The instrument can also be scored as two domains: limitations on life and emotional distress [26]. Validated for use in a UK sample, the scale has been found to have excellent reliability and validity with a Cronbach's alpha of 0.952 for the overall scale, 0.952 for the limitations on life subscale, and 0.860 for the emotional distress subscale [26].
The HADS [27] is a 14-item measure of anxiety and depression used in both hospital and community settings. The questionnaire gives clinically meaningful results as a psychological screening tool and can help in assessing the symptom severity and clinical "caseness" of anxiety disorders and depression in patients with illness and in the general population. The HADS provides separate scores for anxiety and depression, ranging in each from 0 to 21 , with $0-7$ indicating "normal" or no anxiety or depression, 8-10 indicating mild, 11-14 indicating moderate, and 15-21 indicating severe anxiety or depression; scores of $\geq 11$ indicate probable "caseness" [27]. Population norms related to the proportion of people reporting probable clinical caseness in the UK (based on adults aged 25 to 65 years) have been estimated at $12.5 \%$ (males) and $19 \%$ (females), with an average for males and females of $15.8 \%$ for anxiety and $6.9 \%$ for depression [28]. The HADS has been validated many times in different populations, with internal consistency for the anxiety scale ranging from $\alpha=0.68-0.93$ (mean: 0.83 ) and the depression scale ranging from $\alpha=0.67$ 0.90 (mean: 0.82) [29].

The FAIM-PF [30] consists of four items related to the parent's perception of their child's likelihood of allergic reaction events (accidentally ingesting the food to which they are allergic, having a severe reaction, dying from their food allergy, effectively treating themselves when needed). Each item is answered on a 7-point scale, with FAIM scores ranging from 1 (extremely unlikely) to 7 (extremely likely).

\section{Analysis}

Demographic and clinical characteristics were analysed using descriptive statistics. The FAQL-PB and HADS were scored according to their published scoring instructions [25-27]. In line with recommendations of the National Institute for Health and Care Excellence, EQ-5D-5L data were scored using the van Hout et al. [23] mapping function. Pearson's, point biserial, and Spearman's correlations (where data were not normally distributed) were conducted as appropriate to explore relationships between variables. Correlations were interpreted in line with Cohen's guidelines: small: 0.10 to $<0.30$; moderate: 0.30 to $<0.50$; large: $\geq 0.50$ [31]. To explore the impact of caregiver and child gender on caregiver burden, two-way ANOVA (analysis of variance) and Chi square tests were conducted. Chi square tests were also conducted to explore the association between peanut allergy severity and caregiver career impact. To further explore which outcomes significantly predicted caregiver impact, multivariate ordinary least squares regression models were conducted. To assess whether EQ-5D and HADS scores were significantly 
different from population norms, one-sample t-tests and one-sample tests of proportion were conducted as appropriate. Results of statistical tests were considered statistically significant if $\mathrm{p}$ values were below 0.05 . All analyses were conducted using Stata version 16.0.

\section{Results}

The survey information and link were sent to 1330 panel members; 100 caregivers were eligible and completed the survey. Demographics and clinical characteristics of the caregivers and their children are shown in Table 1. The caregivers had a mean age of 40 years (SD 7.6; range
21-65 years), and their children with peanut allergy had a mean age of 10 years (SD 3.4; range 4-15 years). The sample contained male (45\%) and female (55\%) caregivers. Parents and children had high proportions of allergic rhinitis (parents 22\%, children 36\%), asthma (parents 20\%, children 34\%), and skin disorders (parents $17 \%$, children $26 \%$ ).

\section{Impact of caregiving}

Summaries of the impact of being a caregiver to a child with peanut allergy relative to levels of anxiety and depression as well as generic and food-allergy-specific

Table 1 Caregiver and child demographic and clinical characteristics

\begin{tabular}{|c|c|c|c|}
\hline \multicolumn{2}{|l|}{ Characteristic } & \multirow{2}{*}{$\begin{array}{l}\text { Caregivers }(\mathbf{N}=\mathbf{1 0 0}) \\
39.49(7.59)\end{array}$} & \multirow{2}{*}{$\begin{array}{l}\text { Children }(\mathbf{N}=100) \\
9.82(3.42)\end{array}$} \\
\hline Age, years & Mean (SD) & & \\
\hline & Min-max & $21-65$ & $4-15$ \\
\hline Female & $\mathrm{N}$ & 55 & 42 \\
\hline \multirow[t]{4}{*}{ Ethnicity, n } & White & 85 & 86 \\
\hline & Black & 4 & 0 \\
\hline & Asian & 10 & 9 \\
\hline & Mixed race & 1 & 5 \\
\hline \multirow[t]{3}{*}{ Main occupation, n } & Employed outside the home & 89 & - \\
\hline & Looking after family and/or home & 6 & - \\
\hline & Other & 5 & - \\
\hline \multirow[t]{7}{*}{ Comorbidities, n } & Allergic rhinitis & 22 & 36 \\
\hline & Asthma & 20 & 34 \\
\hline & Eating disorder & 7 & 6 \\
\hline & Skin disorder & 17 & 26 \\
\hline & Stress & 13 & 5 \\
\hline & Other & 16 & 11 \\
\hline & None & 37 & 28 \\
\hline \multirow[t]{2}{*}{ Caregiver, food allergy, $\mathrm{n}$} & Peanut allergy & 10 & - \\
\hline & Other food allergy & 11 & - \\
\hline \multirow[t]{2}{*}{ Child, food allergies other than peanut, n (\%) } & No & - & $76(76.0)$ \\
\hline & Yes & - & $24(24.0)$ \\
\hline \multirow[t]{7}{*}{ If "Yes," food allergy, n (\%) } & Celery & - & $2(8.3)$ \\
\hline & Cow milk/dairy products & - & $6(25.0)$ \\
\hline & Egg & - & $11(45.8)$ \\
\hline & Fish/shellfish & - & $1(4.2)$ \\
\hline & Soya beans/other legumes & - & $1(4.2)$ \\
\hline & Other nuts & - & $11(45.8)$ \\
\hline & Other & - & $5(21.0)$ \\
\hline Prescribed an AAl, n & Yes & & 71 \\
\hline Experienced life-threatening event (lifetime n) & Yes & & 34 \\
\hline Number of reactions (lifetime) & Mean (SD) & & $11.98(28.2)$ \\
\hline \multirow[t]{3}{*}{ Peanut allergy severity as reported by caregiver, $\mathrm{n}$} & Mild & - & 13 \\
\hline & Moderate & - & 66 \\
\hline & Severe & - & 21 \\
\hline
\end{tabular}

$A A /$ adrenaline autoinjector, $n$ sample size, $S D$ standard deviation 
measures of HRQL are presented in Table 2 and Fig. 1. All health-outcome measures were highly significantly correlated with each other ( $r$ 's $=0.42-0.65$, p's $<0.001$ ), indicating medium to large effect sizes [31]. Table 2 shows that caregivers' mean anxiety levels overall and for each subgroup (peanut allergy severity, caregiver gender) are all above the normal range (HADS normal range: scores of $0-7$ ). The mean scores are significantly higher than the population norm [28] for the overall sample $(t=4.00, p<0.001)$, males $(t=3.07, p<0.001)$, females $(t=2.44, p<0.05)$, and for those who rate their child's peanut allergy as moderate $(\mathrm{t}=3.44, \mathrm{p}<0.001)$ or

Table 2 Caregiver-reported measures of burden by gender and child peanut allergy severity

\begin{tabular}{|c|c|c|c|c|c|c|c|c|}
\hline & \multirow[t]{3}{*}{$\mathrm{N}$} & \multicolumn{2}{|l|}{ EQ-5 Da } & \multicolumn{2}{|l|}{ HADS $^{\mathbf{b}}$} & \multicolumn{3}{|l|}{ FAQL-PB } \\
\hline & & Utility & VAS & Anxiety & Depression & Total score & Emotional distress & Life limitations \\
\hline & & Mean (SD) & Mean (SD) & Mean (SD) & Mean (SD) & Mean (SD) & Mean (SD) & Mean (SD) \\
\hline Total sample & 100 & $0.873(0.209)$ & $79.96(17.70)^{*}$ & $8.09(4.85)^{* *}$ & $4.93(4.20)^{*}$ & $2.98(1.56)$ & $2.96(1.63)$ & $3.02(1.52)$ \\
\hline \multicolumn{9}{|c|}{ Caregiver gender } \\
\hline Male & 45 & $0.867(0.243)$ & $79.00(17.09)^{*}$ & $7.73(4.86)^{* *}$ & $4.89(4.02)$ & $3.00(1.50)$ & $2.98(1.58)$ & $3.03(1.44)$ \\
\hline Female & 55 & $0.879(0.179)$ & 80.75 (18.30) & $8.38(4.87)^{*}$ & $4.96(4.38)$ & $2.97(1.61)$ & 2.95 (1.69) & 3.01 (1.59) \\
\hline \multicolumn{9}{|c|}{ Child PA severity } \\
\hline Mild & 13 & $0.913(0.204)$ & $83.08(11.43)$ & $5.92(4.23)$ & $4.31(3.99)$ & $2.48(1.37)$ & $2.50(1.48)$ & $2.45(1.21)$ \\
\hline Moderate & 66 & $0.888(0.185)$ & $80.18(17.41)^{*}$ & $8.26(4.98)^{* *}$ & $5.23(4.44)^{*}$ & $2.93(1.58)$ & $2.92(1.65)$ & $2.95(1.54)$ \\
\hline Severe & 21 & $0.803(0.273)$ & $77.33(21.77)$ & $8.91(4.63)^{*}$ & $4.38(3.57)$ & $3.45(1.54)$ & $3.40(1.64)$ & $3.56(1.49)$ \\
\hline
\end{tabular}

FAQL-PB Food Allergy Quality of Life-Parental Burden, HADS Hospital Anxiety and Depression Scale, PA peanut allergy, SD standard deviation, UK United Kingdom, VAS, visual analogue scale

a EQ-5D: Utility index scores range from 0 (dead) to 1 (full health); VAS ranges from 0 to 100 . UK population norm: 18-64-year-olds: overall: utility: 0.885, VAS: 84.72; males: mean utility $=0.880$, mean VAS $=85.22$; females: mean utility $=0.888$, mean VAS $=84.38$ [32]

b Scores range from 0 to $21: 0-7=$ "normal" or no anxiety or depression, $8-10=$ mild, $11-14=$ moderate, $15-21=$ severe anxiety or depression. Scores of $\geq 11$ indicate probable "caseness." UK population norms: anxiety $=6.15$, depression $=3.98$ [28]

*Significantly different from UK population norms $(p<0.05)$

**Significantly different from UK population norms $(p<0.001)$

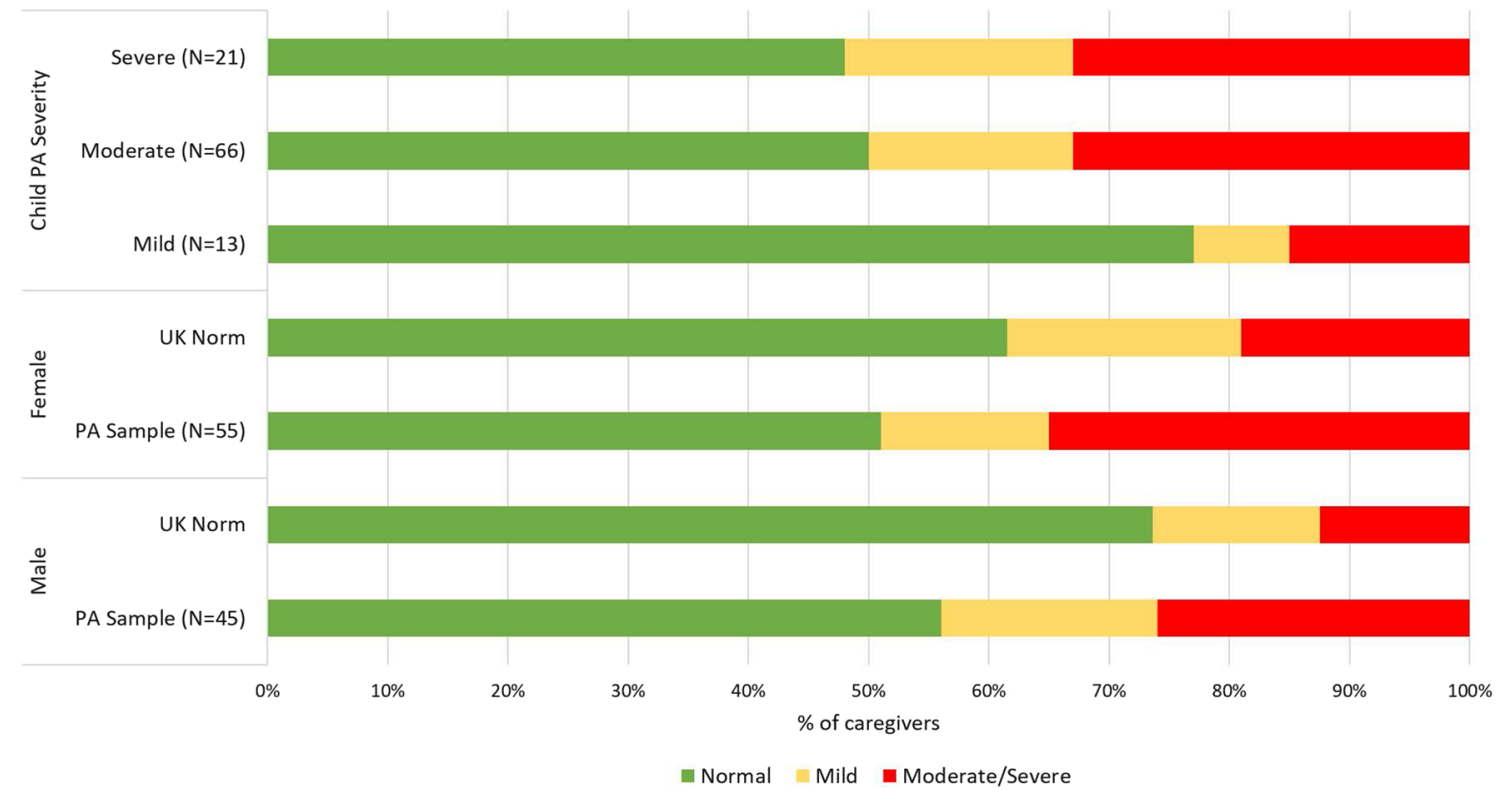

Fig. 1 Proportion of HADS Anxiety categories (normal, mild, moderate/severe) by gender and child's peanut allergy severity. HADS Hospital Anxiety and Depression Scale, PA peanut allergy, UK United Kingdom 
severe $(t=2.73, p<0.05)$. Caregivers' depression mean scores for each subgroup all fall within the normal range (HADS score of 0-7) but are significantly higher than UK population norms overall $(\mathrm{t}=2.26, \mathrm{p}<0.05)$. Similarly, caregiver rates of probable clinical anxiety (moderate/ severe HADS scores of $>10$ ) are approximately double the UK population norms (UK norms: mean $=15.75 \%$, males $=12.5 \%$, females $=19 \%)$ and significantly higher for the total sample $(31 \% ; \mathrm{z}=4.2, \mathrm{p}<0.001)$, males $(26 \%$, $\mathrm{z}=2.9, \mathrm{p}<0.01)$, females $(35 \%, \mathrm{z}=2.9, \mathrm{p}<0.001)$, and those reporting a child with moderate peanut allergy $(33 \%, \mathrm{z}=3.9, \mathrm{p}<0.001)$ or severe peanut allergy $(33 \%$, $\mathrm{z}=2.2, \mathrm{p}<0.05)$ (Fig. 1).

Overall, generic HRQL, as measured by the EQ-5D utility index, was similar to UK population norms, although VAS scores overall were significantly lower than population norms (UK norm for those aged 18-64 years mean utility overall $=0.885$, mean $\mathrm{VAS}=84.72$ [32]; VAS compared to population norm: $t=-2.69$, $\mathrm{p}<0.05)$. However, in the subgroup that perceived their children to have severe peanut allergy, generic HRQL was lower than norms using both utility index (mean 0.803 , population norm 0.885 ) and VAS (mean 77.22, population norm 84.72), yet these differences were not significant $(p>0.05)$ considering the small sample size of the "severe" subgroup. Disutility associated with having a child with increased peanut allergy severity ranged from
0.025 (mild utility $=0.913$ vs moderate utility $=0.888$ ) to 0.11 (mild utility $=0.913$ vs severe utility $=0.803$ ), with a mean disutility of 0.068 (see Table 2 for mean utility values). The utility decrement was largely driven by the EQ-5D anxiety and depression domain: $44 \%$ of caregivers reported being at least slightly anxious or depressed, compared with those reporting at least slight problems with self-care (7\%), mobility (9\%), usual activities (17\%), and pain or discomfort (19\%).

The FAQL-PB food-allergy-specific quality-of-life data suggest minimal (mean scores of 2-3) to moderate (mean scores of 3-4) levels of trouble/burden. The results show a statistically significant increase in caregiver burden among those with children reported to have severe versus mild peanut allergy in the FAQL-PB limitations on life domain $(B=6.64,95 \%$ CI $0.36-12.92, p<0.05)$. To illustrate this burden with more concrete descriptive examples of the impact, Fig. 2 shows the proportion of caregivers who reported being "very" or "extremely" burdened with respect to specific activities and concerns (preparing meals, social limitations, others' attitudes, fear of reactions) according to their child's peanut allergy severity.

Table 3 presents absenteeism, productivity, and career impact results. The overall mean number of days absent in the last 12 months and productivity impacted among caregivers currently in paid employment due to

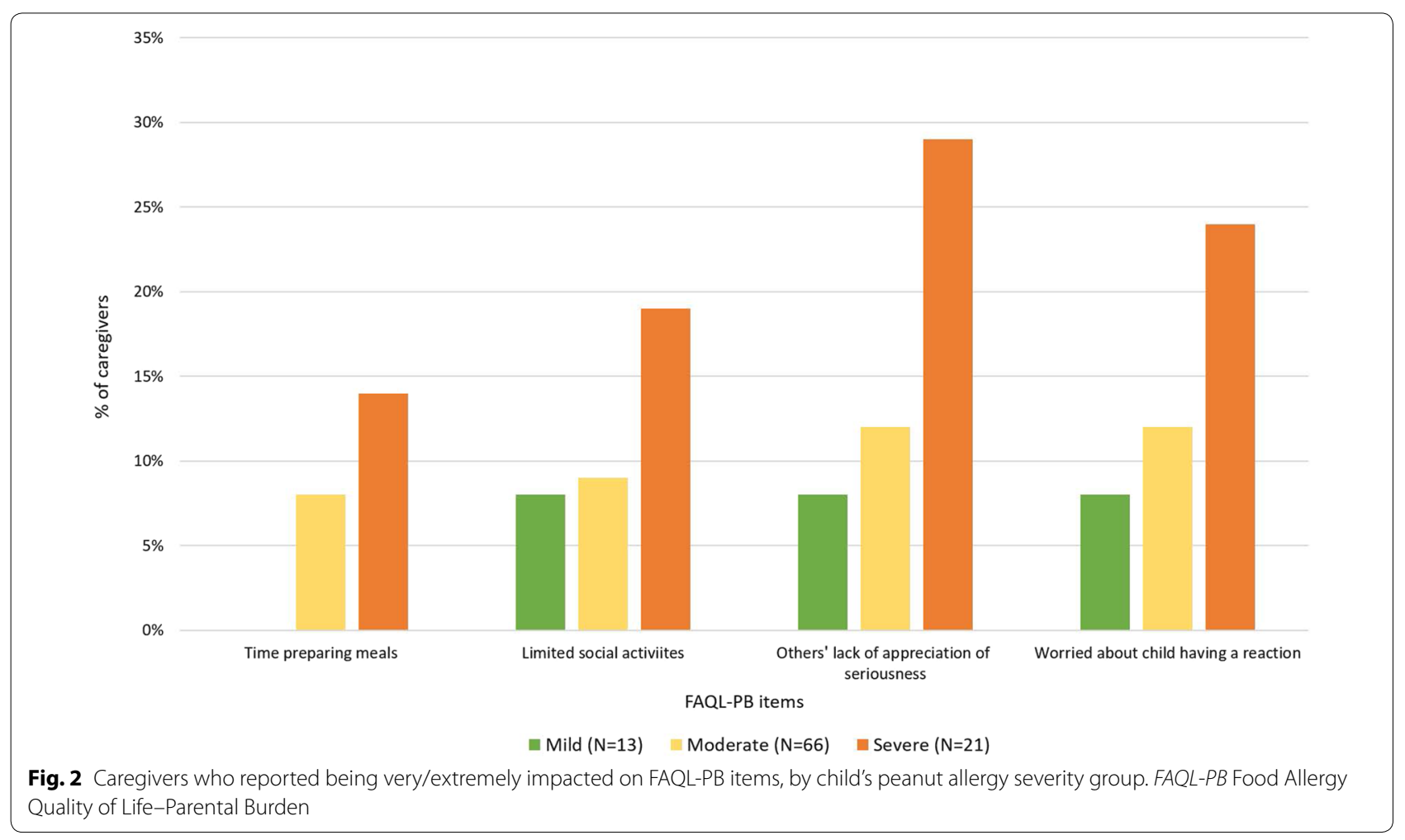


Table 3 Caregiver-reported absenteeism, productivity, and career impact by gender and child peanut allergy severity

\begin{tabular}{|c|c|c|c|c|c|}
\hline & \multicolumn{3}{|c|}{ Currently employed } & \multicolumn{2}{|c|}{ Total Sample } \\
\hline & $\mathrm{N}$ & $\begin{array}{l}\text { Days absent from work (last } \\
12 \text { months) }\end{array}$ & $\begin{array}{l}\text { Days productivity impacted (last } \\
12 \text { months) }\end{array}$ & $\mathrm{N}$ & $\begin{array}{l}\text { Negative career } \\
\text { impact (overall): } \\
\text { Yes }\end{array}$ \\
\hline & & Mean (SD) & Mean (SD) & & $\%$ \\
\hline Total & 91 & $1.60(2.20)$ & $1.87(3.64)$ & 100 & 22 \\
\hline \multicolumn{6}{|c|}{ Caregivers by gender } \\
\hline Male & 45 & $1.87(2.36)$ & $1.71(2.73)$ & 45 & 23 \\
\hline Female & 46 & $1.35(2.01)$ & $2.02(4.38)$ & 55 & 22 \\
\hline \multicolumn{6}{|c|}{ Severity of child's PA } \\
\hline Mild & 12 & $1.08(2.47)$ & $0.50(1.24)$ & 13 & 0 \\
\hline Moderate & 61 & $1.67(2.12)$ & $1.84(3.84)$ & 66 & 20 \\
\hline Severe & 18 & $1.72(2.35)$ & $2.89(3.83)$ & 21 & 43 \\
\hline
\end{tabular}

$N$ sample size, $P A$ peanut allergy

their child's allergy were $\mathrm{M}=1.6$ (SD: 2.2) and $\mathrm{M}=1.9$ (SD: 3.6), respectively. Absenteeism and productivity impacts increased with severity of child's allergy, but not significantly $(\mathrm{p}>0.05)$; however, career impact was significantly associated with increased severity $\left(\chi^{2}=9.19\right.$, $\mathrm{p}=0.01$ ), with $43 \%$ of caregivers of children with severe peanut allergy reporting some career impact (e.g., having to change job or stop work or having restricted career choices).

\section{Relationship between gender and caregivers' burden}

Neither caregiver gender nor child gender were significantly correlated with any of the measures of caregiver burden (all $r$ 's $<0.2$, all p's $>0.05$ ). ANOVAs and Chi square tests showed that caregiver and child gender did not have any significant main or interaction effects on any of the measures of caregiver burden (all p's $>0.05$ ).

\section{Factors impacting caregiver burden}

The significant correlations between measures of burden and potential predictors of burden are detailed in Table 4 . All other potential predictors (adrenaline autoinjector use, caregiver and child gender, child age) were not significantly associated with outcome assessments.

Multivariate regression models for each outcome assessment are presented in Table 5. As the number of reactions in the past 12 months and in the child's lifetime are not independent of each other, these were run in separate models. Also, given the high correlations between FAIM items and total FAIM score, only the

Table 4 Correlations between caregiver burden outcomes and potential predictors of burden

\begin{tabular}{|c|c|c|c|c|c|c|c|}
\hline & \multicolumn{2}{|l|}{ EQ-5D } & \multicolumn{3}{|l|}{ FAQL-PB } & \multicolumn{2}{|l|}{ HADS } \\
\hline & Utility & VAS & Total & Emotional & Limitations & Anxiety & Depression \\
\hline Proxy-reported severity & $-0.201^{*}$ & -0.035 & 0.187 & 0.167 & $0.208^{*}$ & 0.168 & 0.004 \\
\hline Confidence & 0.004 & $0.199^{*}$ & $-0.229^{*}$ & $-0.203^{*}$ & $-0.266^{* *}$ & $-0.215^{*}$ & $-0.323^{* *}$ \\
\hline Life threat, past 12 mo & $-0.330^{* * *}$ & $-0.248^{*}$ & $0.324^{* *}$ & $0.327^{* * *}$ & $0.295^{* *}$ & $0.250^{*}$ & 0.156 \\
\hline Life threat, lifetime & $-0.278^{* *}$ & $-0.213^{*}$ & $0.302^{* *}$ & $0.286^{* *}$ & $0.312^{* *}$ & 0.152 & 0.014 \\
\hline Reactions, past $12 \mathrm{mo}$ & $-0.262^{* *}$ & $-0.354^{* * *}$ & $0.385^{* * *}$ & $0.383^{* * *}$ & $0.380^{* * *}$ & $0.226^{*}$ & $0.344^{* * *}$ \\
\hline Reactions, lifetime & $-0.317^{* *}$ & $-0.327^{* * *}$ & $0.377^{* * *}$ & $0.367^{* * *}$ & $0.379^{* * *}$ & $0.239^{*}$ & $0.235^{*}$ \\
\hline FAIM Total & $-0.398^{* * *}$ & $-0.344^{* * *}$ & $0.602^{* * *}$ & $0.588^{* * *}$ & $0.587^{* * *}$ & $0.400^{* * *}$ & $0.379^{* * *}$ \\
\hline FAIM Ingest peanut & $-0.349^{* * *}$ & $-0.387^{* * *}$ & $0.617^{* * *}$ & $0.612^{* * *}$ & $0.584^{* * *}$ & $0.440^{* * *}$ & $0.444^{* * *}$ \\
\hline FAIM Severe reaction & $-0.263^{* *}$ & $-0.220^{*}$ & $0.438^{* * *}$ & $0.423^{* * *}$ & $0.440^{* * *}$ & $0.336^{* *}$ & $0.258^{* *}$ \\
\hline FAIM Dying & $-0.418^{* * *}$ & $-0.360^{* * *}$ & $0.551^{* * *}$ & $0.537^{* * *}$ & $0.542^{* * *}$ & $0.398^{* * *}$ & $0.410^{* * *}$ \\
\hline FAIM Treatment & $0.268^{* *}$ & -0.161 & $0.368^{* * *}$ & $0.360^{* * *}$ & $0.358^{* * *}$ & $0.240^{*}$ & 0.131 \\
\hline
\end{tabular}

FAIM Food Allergy Independent Measure, FAQL-PB Food Allergy Quality of Life-Parental Burden, HADS Hospital Anxiety and Depression Scale, VAS visual analogue scale

${ }^{*} \mathrm{p}<0.05,{ }^{* *} \mathrm{p}<0.01,{ }^{* * *} \mathrm{p}<0.001$ 
Table 5 Multiple regression models with caregiver burden outcome measures as dependent variables

\begin{tabular}{|c|c|c|c|c|c|}
\hline \multirow[t]{2}{*}{ Outcome/predictors } & & \multirow[t]{2}{*}{ B } & \multirow[t]{2}{*}{ SE } & \multicolumn{2}{|l|}{$95 \% \mathrm{Cl}$} \\
\hline & & & & Lower & Upper \\
\hline \multicolumn{6}{|l|}{ EQ-5D Utility } \\
\hline FAIM Total & & $-0.011^{* *}$ & 0.004 & -0.020 & -0.003 \\
\hline Life-threat. in past 12 mo (Ref: No) & Yes & -0.089 & 0.046 & -0.181 & 0.004 \\
\hline \multirow[t]{2}{*}{ Reactions in past 12 mo, n (Ref: None) } & 1 & -0.015 & 0.060 & -0.133 & 0.104 \\
\hline & 2 or more & -0.076 & 0.054 & -0.183 & 0.032 \\
\hline \multirow[t]{2}{*}{ Proxy-reported severity (Ref: Mild) } & Moderate & -0.017 & 0.058 & -0.132 & 0.097 \\
\hline & Severe & -0.053 & 0.069 & -0.190 & 0.084 \\
\hline \multicolumn{6}{|l|}{ EQ-5D VAS } \\
\hline FAIM total & & $-0.907^{* *}$ & 0.341 & -1.583 & -0.230 \\
\hline Confidence & & $3.978^{*}$ & 1.947 & -0.128 & 7.568 \\
\hline Life-threat. in past 12 mo (Ref: No) & Yes & -4.135 & 3.937 & -11.952 & 3.682 \\
\hline \multirow[t]{2}{*}{ Reactions in past 12 mo, $n$ (Ref: None) } & 1 & -3.706 & 4.984 & -13.602 & 6.190 \\
\hline & $2+$ & $-9.394^{*}$ & 4.585 & -18.497 & -0.290 \\
\hline \multicolumn{6}{|l|}{ HADS anxiety } \\
\hline FAIM total & & $0.336^{* *}$ & 0.927 & 0.149 & 0.518 \\
\hline Caregiver confidence & & $-1.287^{*}$ & 0.530 & -2.338 & -0.235 \\
\hline Life-threat. in past 12 mo (Ref: No) & Yes & 1.377 & 1.071 & -0.750 & 3.504 \\
\hline \multirow[t]{2}{*}{ Reactions in past 12 mo, $\mathrm{n}$ (Ref: None) } & 1 & 0.822 & 1.356 & -1.871 & 3.515 \\
\hline & $2+$ & 1.044 & 1.248 & -1.433 & 3.521 \\
\hline \multicolumn{6}{|l|}{ HADS depression } \\
\hline FAIM_Q1_sum & & $0.272^{* *}$ & 0.076 & 0.121 & 0.424 \\
\hline Caregiver confidence & & $-1.557^{* *}$ & 0.436 & -2.423 & -0.691 \\
\hline Life-threat. in past 12 mo (Ref: No) & Yes & -0.134 & 0.882 & -1.886 & 1.617 \\
\hline \multirow[t]{2}{*}{ Reactions in past 12 mo, $\mathrm{n}$ (Ref: None) } & 1 & 1.988 & 1.117 & -0.229 & 4.206 \\
\hline & $2+$ & $2.750 * *$ & 1.027 & 0.710 & 4.790 \\
\hline \multicolumn{6}{|l|}{ FAQL-PB total } \\
\hline FAIM total & & $2.766^{* * *}$ & 0.420 & 1.931 & 3.601 \\
\hline Caregiver confidence & & $-7.321^{* *}$ & 2.402 & -12.091 & -2.553 \\
\hline Life-threat. in past 12 mo (Ref: No) & Yes & 8.871 & 6.150 & -3.340 & 21.081 \\
\hline \multirow[t]{2}{*}{ Reactions in past 12 mo, $\mathrm{n}$ (Ref: None) } & 1 & 8.871 & 6.150 & -3.340 & 21.081 \\
\hline & $2+$ & $12.228^{*}$ & 5.657 & -0.995 & 23.461 \\
\hline \multicolumn{6}{|l|}{ FAQL-PB life limitations } \\
\hline FAIM total & & $0.897^{* * *}$ & 0.150 & 0.599 & 1.196 \\
\hline Caregiver confidence & & $-2.959^{* *}$ & 0.830 & -4.606 & -1.311 \\
\hline Life-threat. in past 12 mo (Ref: No) & Yes & 1.710 & 1.663 & -1.593 & 5.013 \\
\hline \multirow[t]{2}{*}{ Reactions in past 12 mo, n (Ref: None) } & 1 & 4.176 & 2.134 & -0.061 & 8.414 \\
\hline & $2+$ & $4.748^{*}$ & 1.946 & 0.883 & 8.612 \\
\hline \multirow[t]{2}{*}{ Proxy-reported severity (Ref: Mild) } & Moderate & 2.789 & 2.063 & -1.308 & 6.886 \\
\hline & Severe & 4.157 & 2.468 & -0.745 & 9.059 \\
\hline \multicolumn{6}{|l|}{ FAQL-PB emotions } \\
\hline FAIM Total & & $1.828^{* * *}$ & 0.294 & 1.245 & 2.412 \\
\hline Caregiver confidence & & $-4.427^{*}$ & 1.678 & -7.759 & -1.095 \\
\hline Life-threat. in past 12 mo (Ref: No) & Yes & 5.067 & 3.394 & -1.672 & 11.806 \\
\hline \multirow[t]{2}{*}{ Reactions in past 12 mo, n (Ref: None) } & 1 & 5.239 & 4.296 & -3.292 & 13.769 \\
\hline & $2+$ & 7.672 & 3.952 & -0.175 & 15.520 \\
\hline
\end{tabular}

B standardized beta coefficient, Cl confidence interval, FAIM Food Allergy Independent Measure, FAQL-PB Food Allergy Quality of Life - Parental Burden, HADS Hospital Anxiety and Depression Scale, Ref reference category, SE standard error, VAS visual analogue scale

${ }^{*} \mathrm{p}<0.05,{ }^{* *} \mathrm{p}<0.01,{ }^{* * *} \mathrm{p}<0.001$ 
total score was included in the models. The regression models show that for all measures of caregiver burden, the caregivers' increased expectation of negative outcomes as measured by the FAIM (e.g., perception of risk of dying, having a severe reaction, or accidental ingestion of allergen) significantly increased burden. For all except EQ-5D utility, caregiver confidence also significantly predicted burden, with higher confidence associated with lower burden. The number of reactions in the past 12 months was the only other relatively consistent predictor of burden (EQ-5D VAS, FAQL-PB total and limitation domain, and HADS depression), with significantly increased burden associated with 2 or more reactions in the past 12 months. All models were repeated with "lifetime" reactions or life-threatening events, but these were only significant predictors for (1) FAQL-PB limitations domain, where having had a lifethreatening event was associated with a 3-point increase in score $(\mathrm{B}=2.97, \mathrm{p}<0.05)$ and (2) EQ-5D VAS, where having had $\geq 6$ reactions in one's lifetime versus zero reactions was associated with a 9-point decrease on the VAS $(B=-8.90, p<0.05)$. The significant association between a child's proxy-reported severity and FAQL-PB total score, and between severity and EQ-5D utility, were no longer significant when other predictors were considered.

\section{Discussion}

This study helps provide a better understanding of the impact, and its driving factors, associated with being a caregiver to a child with peanut allergy in the UK. The study highlighted the psychological burden experienced by caregivers of children with peanut allergy, revealing levels of anxiety and depression significantly higher than UK population norms for males (anxiety and depression) and females (anxiety only) and rates of probable clinical anxiety significantly higher than the UK population. There was a trend toward poorer health utility values among caregivers who perceived their child to have severe peanut allergy relative to the general population, although differences were not statistically significant, likely due to the small sample size of the "severe" group. These peanut-allergy-specific caregiver utility values are the first to be published and indicate that the HRQL burden for caregivers of children with peanut allergy is largely driven by the levels of anxiety and depression experienced. Furthermore, caregivers of children with severe peanut allergy also reported significant impacts on their careers and limitations to their HRQL. Notably, caregiver gender did not impact burden, as the study indicated that male and female caregivers are equally anxious and suffer the same level of negative career, productivity, and HRQL impact due to their child's peanut allergy.

This study found that caregivers' expectations of outcome, specifically their perception of their child's risk of allergen exposure, having a severe reaction, dying, or being able to effectively treat themselves (measured using the FAIM) independently predicted all measures of caregiver burden. Caregiver confidence was also an independent predictor of burden (for all measures except utility). Objective measures of severity such as lifethreatening events and number of reactions were also significantly associated with burden; however, these did not retain significance in multivariate models, suggesting that these events are captured within the measures of caregivers' expectations and levels of confidence.

The results of this study support previous research showing a negative impact of peanut allergy on caregiver HRQL [18]. In contrast to previous research showing a gender difference in caregiver burden in peanut allergy and food allergy, the current study suggests there is no difference, as both male and female caregivers reported a negative impact. Similarly, comparable levels of career impact were reported by male and female caregivers, suggesting equal involvement in peanut-allergy-related care. This may support previous findings that any gender differences may be related to the level of involvement rather than gender [17]. In addition, previous research showing differences in responses based on the gender of caregivers of children with peanut allergy [18] used a smaller sample size recruited from a specialist allergy center and was published 10 years ago; the more current data reported here may reflect increased shared responsibility between parents.

This study found that caregiver expectation of outcome measured using FAIM was the key driver of caregiver burden in peanut allergy; this is in contrast to previous research that found the FAIM was not a significant predictor of caregiver psychosocial impact [33]. However, caregiver self-efficacy (confidence) has been shown to predict the psychosocial impact of food allergy [14], which is consistent with the current study's finding that caregiver confidence predicted several measures of caregiver burden. A number of studies have shown that food allergy reaction history impacts caregiver burden $[8$, $10,11]$, although these studies did not include FAIM in the same regression model. In the current study, reaction history in terms of the number of reactions and having experienced a life-threatening event showed some impact on caregiver burden but was not the main driver when parental expectation of outcome (measured by FAIM) was also included.

Some limitations should be considered when interpreting the results of this study. The research was 
conducted in the UK only; therefore, the results may not be generalizable to caregivers in other countries. In addition, the sample size of 100 is relatively small and so some of the analyses may be underpowered, such as the differences between the severe peanut allergy population versus general population norms. Another limitation is that the severity of peanut allergy can be difficult to objectively measure, given that food allergic reactions are unpredictable, and severity is not determined by test results or history of reaction; clinical severity as reported by parents should be considered a subjective measure. Thus, it is important to interpret results of analyses exploring associations between peanut allergy severity and caregiver impact as reflecting caregiver perception of severity, rather than clinical severity itself. Future research could expand on this study by increasing the sample size, exploring parent and child dyads, and exploring the burden experienced by caregivers of children with peanut allergy in other countries.

\section{Conclusions}

This study highlights the burden experienced by caregivers of children with peanut allergy in the UK, particularly the high levels of anxiety reported by both male and female caregivers. In addition, caregivers of children with severe peanut allergy report significant impacts on their careers and limitations in their HRQL. The study also found that caregiver expectation of outcome, confidence, and several objective measures of severity were significantly associated with caregiver burden.

\section{Abbreviations}

FAIM-PF: Food Allergy Independent Measure-Parent Form; FAQL-PB: Food Allergy Quality of Life-Parental Burden; HADS: Hospital Anxiety and Depression Scale; HRQL: Health-related quality of life; VAS: Visual analogue scale.

\section{Acknowledgements}

This study was supported by Aimmune Therapeutics. Editorial assistance was provided by The Curry Rockefeller Group, LLC and was funded by Aimmune Therapeutics.

\section{Authors' contributions}

RK, SA, KG, JdV, AV supervised the project. RK, SA, KG, JdV, RR and AV wrote the manuscript. RK, SA, KG, JdV, AM, RR and AV reviewed the manuscript. All authors have contributed to and approved the final manuscript.

\section{Funding}

This research was funded by Aimmune Therapeutics.

\section{Availability of data and materials}

Data are available upon reasonable request to the corresponding author

\section{Ethics approval and consent to participate}

The study was reviewed and approved by the Freiburg Ethics Commission International $(\mathrm{FECl})$ prior to participant recruitment ( $\mathrm{FECl}$ code: 017/1938; date: 20 November 2017)

\section{Consent for publication}

Not applicable.

\section{Competing interests}

SA and KG are employees of Acaster Lloyd Consulting Ltd. Acaster Lloyd Consulting Ltd was paid by Aimmune Therapeutics to conduct this study. $\mathrm{JdV}$ is a consultant for Aimmune Therapeutics. AV and RR are employees of Aimmune Therapeutics. AM is a former employee of Aimmune Therapeutics. RK is a consultant for Aimmune Therapeutics.

\section{Author details}

${ }^{1}$ Acaster Lloyd Consulting Ltd, 16 Woburn PI, Bloomsbury, London WC1H OBS, UK. ${ }^{2}$ Independent Consultant to Aimmune Therapeutics, London, UK. ${ }^{3}$ Aimmune Therapeutics, 10 Eastbourne Terrace, London W2 6LG, UK. ${ }^{4}$ Department of Psychology, School of Life and Health Sciences, Aston University, Aston Triangle, Birmingham B4 7ET, UK.

Received: 13 May 2020 Accepted: 29 August 2020

Published online: 25 September 2020

References

1. Venter C, Hasan Arshad S, Grundy J, Pereira B, Bernie Clayton C, Voigt $\mathrm{K}$, et al. Time trends in the prevalence of peanut allergy: three cohorts of children from the same geographical location in the UK. Allergy. 2010;65:103-8.

2. Nwaru BI, Hickstein L, Panesar SS, Roberts G, Muraro A, Sheikh A, et al. Prevalence of common food allergies in Europe: a systematic review and meta-analysis. Allergy. 2014;69:992-1007.

3. Kotz D, Simpson CR, Sheikh A. Incidence, prevalence, and trends of general practitioner-recorded diagnosis of peanut allergy in England, 2001 to 2005. J Allergy Clin Immunol. 2011;127:623-30.

4. Sicherer SH, Noone SA, Muñoz-Furlong A. The impact of childhood food allergy on quality of life. Ann Allergy Asthma Immunol. 2001;87:461-4.

5. Birdi G, Cooke R, Knibb R. Quality of life, stress, and mental health in parents of children with parentally diagnosed food allergy compared to medically diagnosed and healthy controls. J Allergy. 2016;2016:1497375. https://doi.org/10.1155/2016/1497375.

6. Valentine $A Z$, Knibb RC. Exploring quality of life in families of children living with and without a severe food allergy. Appetite. 2011;57:467-74.

7. Primeau MN, Kagan R, Joseph L, Lim H, Dufrense C, Duffy C, et al. The psychological burden of peanut allergy as perceived by adults with peanut allergy and the parents of peanut-allergic children. Clin Exp Allergy. 2000;30:1135-43.

8. Kajornrattana T, Sangsupawanich P, Yuenyongviwat A. Quality of life among caregivers and growth in children with parent-reported food allergy. Asian Pacific J Allergy Immunol. 2018;36:22-6.

9. Knibb RC, Semper H. Impact of suspected food allergy on emotional distress and family life of parents prior to allergy diagnosis. Pediatr Allergy Immunol. 2013;24:798-803.

10. Allen CW, Bidarkar MS, vanNunen SA, Campbell DE. Factors impacting parental burden in food-allergic children. J Paediatr Child Health. 2015;51:696-8.

11. Ward CE, Greenhawt MJ. Treatment of allergic reactions and quality of life among caregivers of food-allergic children. Ann Allergy Asthma Immunol. 2015;114:312-8.

12. Howe L, Franxman T, Teich E, Greenhawt M. What affects quality of life among caregivers of food-allergic children? Ann Allergy Asthma Immunol. 2014;113:69-74.

13. Cortes A, Castillo A, Sciaraffia A. Food allergy: children's symptom levels are associated with mothers' psycho-socio-economic variables. J Psychosom Res. 2018:104:48-54.

14. Knibb RC, Barnes C, Stalker C. Parental self-efficacy in managing food allergy and mental health predicts food allergy-related quality of life. Pediatr Allergy Immunol. 2016;27:459-64. 
15. Williams NA, Hankey M. Support and negativity in interpersonal relationships impact caregivers' quality of life in pediatric food allergy. Qual Life Res. 2015;24:1369-78.

16. Warren CM, Gupta RS, Sohn MW, Oh EH, Lal N, Garfield CF, et al. Differences in empowerment and quality of life among parents of children with food allergy. Ann Allergy Asthma Immunol. 2015;114:117-25.

17. Hoehn JL, Dahlquist LM, Hahn AL, Bollinger ME. Parents of children with food allergy: gender differences in perceived impact and perceived food allergy severity. J Pediatr Psychol. 2017;42:186-97.

18. King RM, Knibb RC, Hourihane JO. Impact of peanut allergy on quality of life, stress and anxiety in the family. Allergy. 2009;64:461-8.

19. Roy KM, Roberts MC. Peanut allergy in children: relationships to health-related quality of life, anxiety, and parental stress. Clin Pediatrics. 2011;50:1045-51.

20. Stensgaard A, Bindslev-Jensen C, Nielsen D. Peanut allergy as a family project: social relations and transitions in adolescence. J Clin Nurs. 2017;26:3371-81.

21. Gupta R, Holdford D, Bilaver L, Dyer A, Holl JL, Meltzer D. The economic impact of childhood food allergy in the United States. JAMA Pediatr. 2013;167:1026-31.

22. Herdman M, Gudex C, Lloyd A, Janssen MF, Kind P, Parkin D, et al. Development and preliminary testing of the new five-level version of EQ-5D (EQ-5D-5L). Quality Life Res. 2011;20:1727-36.

23. Van Hout B, Janssen MF, Feng YS, Kohlmann T, Busschbach J, Golicki $D$, et al. Interim scoring for the EQ-5D-5L: mapping the EQ-5D-5L to EQ-5D-3L value sets. Value Health. 2012;15:708-15.

24. Dolan P. Modeling valuations for EuroQol health states. Med Care. 1997;35:1095-108.
25. Cohen BL, Noone S, Muñoz-Furlong A, Sicherer SH. Development of a questionnaire to measure quality of life in families with a child with food allergy. J Allergy Clin Immunol. 2004;114:1159-63.

26. Knibb RC, Stalker C. Validation of the food allergy quality of life-parental burden questionnaire in the UK. Qual Life Res. 2013;22:1841-9.

27. Zigmond AS, Snaith RP. The hospital anxiety and depression scale. Acta Psychiatry Scand. 1983;67:361-70.

28. Breeman S, Cotton S, Fielding S, Jones GT. Normative data for the hospital anxiety and depression scale. Qual Life Res. 2015;24:391-8.

29. Bjelland I, Dahl AA, Haug TT, Neckelmann D. The validity of the Hospital Anxiety and Depression Scale: an updated literature review. J Psychosom Res. 2002;52:69-77.

30. van der Velde JL, Flokstra-de Blok BM, Vlieg-Boerstra BJ, Oude Elberink JN, DunnGalvin A, Hourihane JO, et al. Development, validity and reliability of the food allergy independent measure (FAIM). Allergy. 2010;65:630-5.

31. Cohen J. Statistical power analysis for the behavioral sciences. 2nd ed London: Lawrence Erlbaum; 1988.

32. Janssen B, Szende A. Population norms for the EQ-5D. In: Selfreported population health: an international perspective based on EQ-5D. Dordrecht: Springer; 2014. p. 19-30.

33. Knibb RC, Cortes A, Barnes C, Stalker C. Validation of the English version of the scale for psychosocial factors in food allergy and the relationship with mental health, quality of life, and self-efficacy. J Allergy. 2016;2016:4850940

\section{Publisher's Note}

Springer Nature remains neutral with regard to jurisdictional claims in published maps and institutional affiliations.
Ready to submit your research? Choose BMC and benefit from:

- fast, convenient online submission

- thorough peer review by experienced researchers in your field

- rapid publication on acceptance

- support for research data, including large and complex data types

- gold Open Access which fosters wider collaboration and increased citations

- maximum visibility for your research: over 100M website views per year

At BMC, research is always in progress.

Learn more biomedcentral.com/submissions 